\title{
Effects of temperature changes on soil hydraulic properties
}

\author{
Hongbei Gao ${ }^{a}$, Mingan Shao ${ }^{\mathrm{a}, \mathrm{b}, *}$ \\ a State Key Laboratory of Soil Erosion and Dryland Farming on the Loess Plateau, Institute of Soil and Water Conservation, Chinese Academy of science, \\ Yangling, Shaanxi, PR China \\ ' Institute of Geographical Science and Natural Resources Research, Chinese Academy of Science, Beijing, PR China
}

\section{A R T I C L E I N F O}

\section{Article history:}

Received 29 October 2013

Received in revised form 29 April 2015

Accepted 5 May 2015

\section{Keywords:}

Soil temperature

Soil-water characteristic curve

Hydraulic conductivity

Clay

\begin{abstract}
A B S T R A C T
Accurate simulation of the effects of temperature on soil water movement processes is lacking in the study of hydrothermal interactions in soil systems. Previous research has proposed some likely mechanisms (e.g., surface tension-viscous flow) to explain soil hydraulic properties in relation to temperature, but little research has focused on the temperature dependence of soil particles (e.g., thermal expansion). Using simulation analyses and experimental data, the effect of temperature on soil hydraulic properties was explored focusing on the thermal effect of water surficial properties and soil particle characteristics. Two temperature coefficients, $\lambda$, representing the thermal effect of water surficial properties and $c$, representing the thermal effect of soil particle characteristics are introduced into soil hydraulics formulae to represent temperature dependence. Results show that temperature-dependent changes in water surficial properties including kinematics viscosity, surface tension and water density effects on soil hydraulic properties. Changes in temperature also affect soil particles, soil porosity and the interactive surface between liquid and solid, especially in heavy loam with high clay content. Expected soil hydraulic properties were calculated at three temperatures in two soil types and then compared to corresponding experimental results. Comparison of predicted and experimental soil hydraulic properties revealed overall similarities with a few exceptions. This study represents an initial simulation study of the effects of temperature on soil hydraulic properties.
\end{abstract}

(c)2015 Published by Elsevier B.V.

\section{Introduction}

The effects of temperature on soil hydraulic properties have long been recognized but the mechanisms are far from fully understood. Temperature gradients are not only a driving force of capillary liquid flow but also significantly affect soil hydraulic properties (Hopmans and Dane, 1985; Grant and Bachmann, 2002). A widely accepted mechanism explaining this thermal effect is the surface tension-viscous flow theory (STVF). In the STVF model, the effect of temperature changes on soil hydraulic properties attributes to the thermal response of fluid viscosity and surface tension of liquids in the soil. However, some studies have shown that the STVF imperfectly interprets temperature-dependent changes in soil-water movement (Nimmo and Miller, 1986).

The derivation of the mathematical formula representing the Soil Water Characteristic Curve (SWCC) by Philip and de Vries (1957) was important in furthering understanding of temperaturedependent effects on soil hydraulic properties. In this model, the effect of temperature changes on the SWCC is attributed solely to

\footnotetext{
* Corresponding author.

E-mail address: mashao@ms.iswc.ac.cn (M. Shao).
}

the temperature dependence of water surface tension. Wilkinson and Klute (1962) proposed a thermally driven relationship between soil water pressure head and soil water content and concluded that changes in water surface tension are driven by temperature. These findings have been widely used by researchers to explain experimental results showing increasing soil water pressure head with increasing temperature (Haridasan and Jensen, 1972; Constantz and Murphy, 1991; Bachmann et al., 2002; Grant and Bachmann, 2002). Although this progress has advanced understanding of temperature-dependent effects on soil hydraulic properties, observed results still deviate from predicted results. Some explanations for this gap are the effect of temperature on entrapped air and the presence of contaminants affecting surface tension at the air-water interface.

Saturated and unsaturated hydraulic conductivity and soilwater diffusivity are the basic properties to describe the soil water movement process. Observed increases in hydraulic conductivity at a given water content under increasing temperature are attributed to a decrease in the viscosity of water (Haridasan and Jensen, 1972). However, with increasing temperature there are two conflicting effects of temperature on hydraulic conductivity: an increase in matric potential, and a decrease in viscosity of water 
(Hopmans and Dane, 1985). At a given matric potential, hydraulic conductivity decreases as the amount of water held in soil decreases with increasing temperature. Conversely, a decrease in water viscosity increases soil hydraulic conductivity. Many studies have shown that experimental temperature dependence of hydraulic conductivity is greater than results predicted by models (Flocker et al., 1968; Hopmans and Dane, 1986a; Constantz and Murphy, 1991).

There are four proposed mechanisms to explain the greater temperature dependence of soil water potential and hydraulic conductivity observed in experimental results (Grant and Bachmann, 2002). The first mechanism proposed is an increase in the volume of entrapped air with increasing temperature. This mechanisms increases temperature sensitivity of soil water pressure head. However recent research has questioned this mechanism (Hopmans and Dane, 1986b). The second mechanism is the temperature dependence of water expansion. However, the predictions of this model are not credible at the lowest and highest extremes of capillary pressure (She and Sleep, 1998). The third proposed mechanism is the effect of solutes on the surface tension of water (Chen and Schnitzer, 1978). The last proposed mechanism are temperature-sensitive contact angles (King, 1981). Though these mechanisms shed light on the temperature dependence of soil hydraulic properties, none fully describes the existing results from experiments. Bachmann et al. (2002) suggest that the most likely mechanisms for the considerably greater temperature dependence of capillary pressure are solute effects on surface tension and temperature-induced changes in contact angles.

The temperature dependence of soil structure is a relevant factor influencing hydraulic properties. Increases in temperatures can reduce inter-particle bond strength, which, when coupled with the differential thermal expansion between mineral particles and water can result in a reduction in the void ratio. The expansion of particles also causes a reduction in specific surface area further implying that water holding capacity of particles decreases. However, no reports give a detailed description of this theory (Constantz, 1982; Romero et al., 2001). The objectives of this study are as follows: (1) to determine the effect of temperature on the soil hydraulic properties, and (2) to conduct a preliminary investigation of the mechanisms driving temperature dependence of soil structural changes and hydraulic properties.

\section{Theory}

\subsection{Soil water characteristic curve}

The SWCC describes the relationship between pressure head (water potential) and water content, but almost all SWCC models ignore temperature effects on this relationship. Of the empirical and semi-empirical formulae quantifying this curve, the van Genuchten model derived with a closed-form analytical expression is one of the most flexible (van Genuchten, 1980; van Genuchten and Nielsen, 1985). Saturated volumetric water content $\left(\theta_{s}\right)$, residual volumetric water content $\left(\theta_{r}\right)$ and pressure head $(h)$, were introduced into this model as the initial condition parameters and boundary condition parameters. The other three independent parameters, $\alpha, m$ and $n$, were obtained by fitting the experimental data from given soil samples. To obtain a closed-form expression for hydraulic conductivity, a relationship $(m=1-1 / n)$ was determined artificially in this model. The van Genuchten model for SWCC is more flexible than many others and is widely applied. The model can also be used to estimate hydraulic conductivity parameters through statistical analysis of the pore size distribution. The expression of this model is as follows:
Se $=\frac{1}{\left[1+(\alpha|h|)^{n}\right]^{m}}$

where $S e$ is the effective degree of saturation, $0<S<1$; $\alpha$ is an empirical parameter with a reciprocal value of $h_{d}$, viz., $\alpha=1 / h_{d}, h_{d}$ is the air-entry value; $m$ and $n$ are the empirical constants for pore size distribution parameters affecting the slope of the retention curve of a given soil.

Assuming any temperature $T$ and a reference temperature $T_{o}$, the Van Genutchen model represents temperature dependence effects as follows:

$S e_{T}=\frac{\left[1+\left(\alpha h_{T o}\right)^{n}\right]^{m}}{\left[1+\left(\alpha h_{T}\right)^{n}\right]^{m}} \times S e_{T o}$

If the water content is close to the saturated water content, the soilwater suction is very low. Under such conditions, the values of $h \approx 0$ and $S e \approx 1$. Conversely, if the water content is low, then the value of $(\alpha h)^{n}>>1$ (Shao and Horton, 1998). The number "1" in Eq. (2) can be ignored. A relationship can be derived as follows:

$S e_{T}=\frac{\left(\alpha h_{T o}\right)^{n-1}}{\left(\alpha h_{T}\right)^{n-1}} \times S e_{T o}$

According to Hopmans and Dane (1985), the knowledge of a reference soil-water pressure head $\left(h_{T o}\right)$ at a reference temperature allows the soil water pressure head value at any other temperature to be approximated by:

$h_{T}=\delta h_{T o}$

where $\delta$ is a parameter associated with the effect of temperature on surface tension, $\delta=\sigma_{T} / \sigma_{T o} . \sigma_{T}$ and $\sigma_{T o}$ represents the surface tension of water at any temperature and a reference temperature, respectively. Application of capillary pressure theory and Eq. (4) allows the temperature dependence of SWCC to be determined from Eq. (3):

$S e_{T}=\lambda S e_{T o}$

where:

$\lambda=\left(\frac{\sigma_{T o}}{\rho_{T o}} / \frac{\sigma_{T}}{\rho_{T}}\right)^{n-1}$

where $\lambda$ is determined as a temperature dependent sensitivity parameter, $\rho$ is the density of water, $\mathrm{g} \mathrm{cm}^{-3}$. According to Eqs. (5) and (6), the temperature dependence of the SWCC based on the van Genuchten model accounts for the temperature dependence of

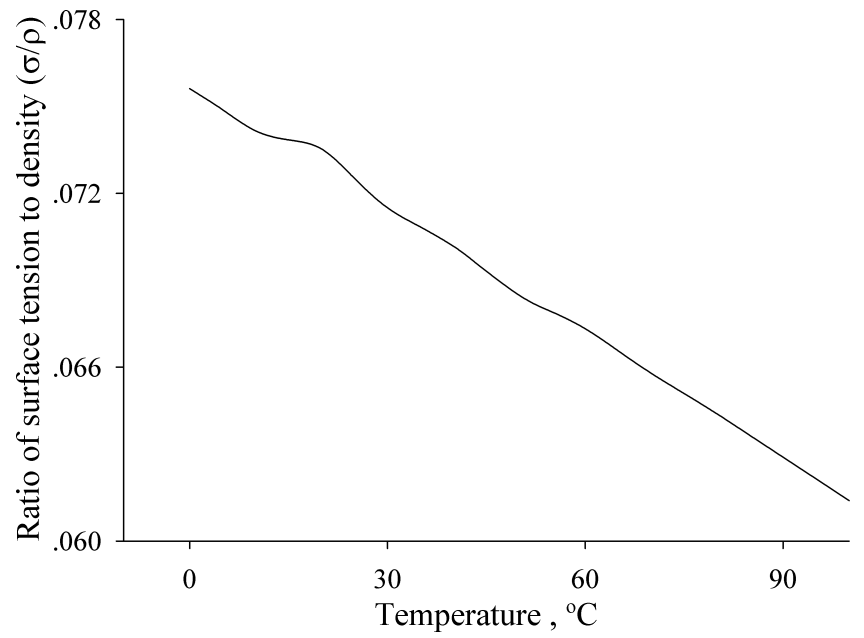

Fig. 1. Changes in the ratio of water surface tension to density $(\sigma / \rho)$ vs temperature $(T) . \sigma$ water surface tension; $\rho$ : water density. 
water surface tension and water density. The ratio of $\sigma / \rho$ for pure water (assumption) with temperature changes was plotted in Fig. 1. The ratio of $\sigma / \rho$ decreases as temperature increases.

\subsection{Saturated hydraulic conductivity}

Saturated hydraulic conductivity $\left(K_{\mathrm{s}}\right)$ is a special coefficient of water flow in soil pores when the water content is at a maximum (while $h=0$ ); an assumption is made that soil porosity is the assembly of numerous interconnected capillaries (Philip, 1957). According to Poiseuille's theory (Poiseuille, 1844; Liu et al., 2014), the formula to describe the process of liquid flow through capillaries is as follows:

$Q=\frac{V}{t}=\frac{\pi R^{4} \Delta P}{8 \eta l}$

where $Q$ is the volume flow rate in the capillary $\left(\mathrm{cm}^{3} \mathrm{~min}^{-1}\right) ; R$ and $l$ are the radius $(\mathrm{cm})$ and the length of the capillary $(\mathrm{cm})$, respectively; and $\eta$ is the dynamic viscosity coefficient, and $\Delta P$ is the pressure difference between the two ends of capillary. At any temperature $T$ and the reference temperature $T_{\mathrm{o}}$, the corresponding dynamic viscosities are set as $\eta_{T}$ and $\eta_{T o}$, respectively. Comparing $Q_{T}$ with $Q_{T o}$, an expression was obtained as follows:

$\frac{\eta_{T}}{\eta_{T o}}=\frac{t_{T} \Delta P_{T}}{t_{T o} \Delta P_{\mathrm{To}}}$

where $\Delta P_{T}$ and $\Delta P_{\text {To }}$ represent the difference between the two ends of capillary at temperature $T$ and the reference temperature $T_{\mathrm{o}}$, respectively. Eq. (9) was then derived as follows:

$\frac{\eta_{T}}{t_{T} \times \rho_{T}}=\frac{\eta_{T o}}{t_{T o} \times \rho_{\mathrm{To}}}=\eta_{G}^{*}$

where $\eta_{G}^{*}$ is a normalization parameter related to the properties of water in a soil capillary.

Dynamic viscosity is a temperature dependent parameter of liquid flow. Eq. (9) indicates that, although changes in temperature result in variations in dynamic viscosity, the ratio between $\eta$ and the product of $t$ and $\rho$ remains constant $\left(\eta_{G}^{*}\right)$. The constant parameter $\eta_{G}^{*}$ is only affected by liquid properties in capillaries. Assuming that the soil pore is full of water, $K_{s}$ is obtained by:

$K_{s}=\frac{R^{2} \Delta h}{8 l} \times \frac{\rho g}{\eta}$

where $g$ is the gravity constant, $\mathrm{ms}^{-2}$. The simplification of Eq. (10) can be derived as follows:

$K_{s} \times v=M$

where $v$ is the kinematic viscosity, $v=\eta / \rho$; and $M$ is a feature parameter of a given soil, $M=R^{2} g \Delta h / 8 l$. For a given soil, the parameter $M$ is constant. According to Eq. (9), the saturated hydraulic conductivity at any temperature $\left(K_{S T}\right)$ can be calculated from:

$K_{S T} \times v_{T}=K_{S T o} \times v_{T o}=M$

where $K_{\text {sTo }}$ represents the saturated hydraulic conductivity at reference temperature; $v_{T}$ and $v_{T o}$ represent the kinematic viscosity, $\mathrm{m}^{2} \mathrm{~s}^{-1}$, at the reference temperature and the soil temperature in question, respectively. This product indicates that the change of $K_{s}$ with temperature is controlled by the temperature dependence of the kinematic viscosity. Assuming $18^{\circ} \mathrm{C}$ as a reference temperature, the ratios of $v_{T o} / v_{T}$ are plotted in Fig. 2 . The results show that this ratio increases with increasing temperature. The rate of increase is approximately 0.026 times for $1{ }^{\circ} \mathrm{C}$ rise.

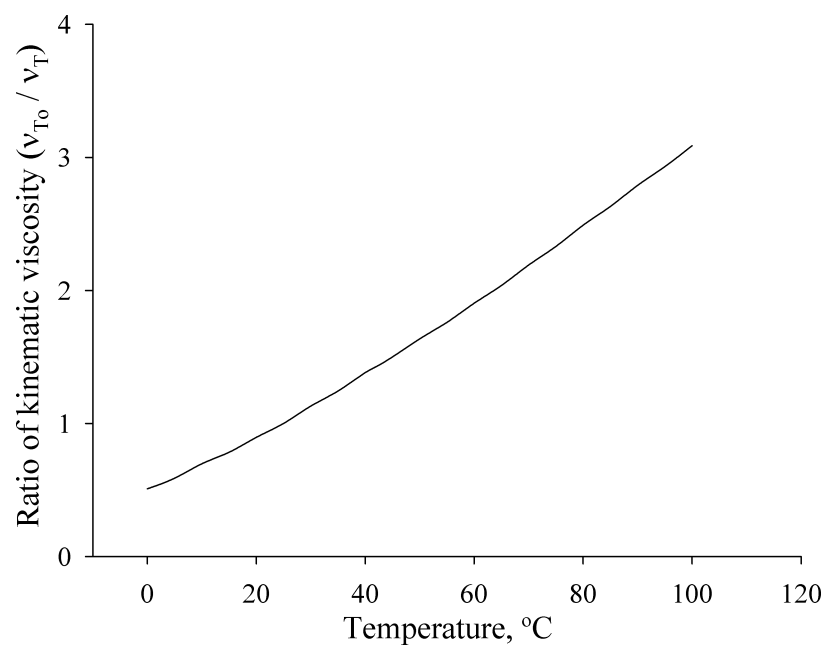

Fig. 2. Changes in the ratio of kinematic viscosity $\left(v_{T o /} \nu_{T}\right)$ vs temperature $(T)$; reference temperature: $T_{\mathrm{O}}=18^{\circ} \mathrm{C}$. $v_{\mathrm{To}}$ : kinematic viscosity at reference temperature; $v_{\mathrm{T}}$ : kinematic viscosity at any temperature.

\subsection{Unsaturated hydraulic conductivity}

Unsaturated hydraulic conductivity, $K(\theta), \mathrm{cm} \mathrm{min}^{-1}$, can be expressed by:

$K(\theta)=K_{s}\left(\frac{\theta}{f}\right)^{2 c+1}$

where $f$ is the soil porosity (\%); $c$ is a grading parameter of the pore diameter. At a reference temperature $\left(T_{0}\right)$ and any temperature $(T)$, the functions are derived as follows:

$K_{T o}(\theta)=K_{s T o}\left(\frac{\theta}{f}\right)^{2 c_{T o}+1}$

$K_{T}(\theta)=K_{S T}\left(\frac{\theta}{f}\right)^{2 c_{T}+1}$

Analysis of the temperature dependence of the SWCC demonstrated the saturation $(\Delta \theta / f)$ variations with changing temperature. Eq. (15) was obtained as follows:

$\frac{\Delta \theta_{T}}{f_{s T}} / \frac{\Delta \theta_{T o}}{f_{s T o}}=\left(\frac{\sigma_{T o} \rho_{T}}{\sigma_{T} \rho_{T o}}\right)^{n-1}=\lambda$

where $\Delta \theta$ is the difference between the soil water content and the residual water content, $\mathrm{cm}^{3} \mathrm{~cm}^{-3}$. Eq. (16) can be derived by substituting Eq. (15) into Eq. (14):

$K_{T}(\theta)=\lambda^{2 c_{T}+1} h_{T o}{ }^{2\left(c_{T o}-c_{T}\right)} \frac{\nu_{T o}}{v_{T}} K_{T o}(\theta)$

In Eq. (16), the term $\lambda^{2 c_{T}+1} v_{T o} / v_{T}$ represents the temperature dependence effects on water properties, including surface tension, kinematic viscosity and water density. An increase in temperature increases the hydraulic conductivity through the decrease of those three parameters. The term $h_{T o}{ }^{2\left(c_{T}-c_{T O}\right)}$ represents the temperature dependent effect on soil pore characteristics. Parameter $c$ represents the distribution characteristic of the pore diameter in soil. For different soil textures, the value of $c$ is difficult to constrain, as it is difficult to directly measure. The following statistical method was employed:

$c=(A-1) / 2$

where parameter A represents the slope of the logarithmic equation of unsaturated hydraulic conductivity and soil water 
content based on measurement:

$A=\frac{\log \left(K(\theta) / K_{s}\right)}{\log (\theta / f)}$

The logarithmic curves of soil hydraulic conductivity of tested soils is shown in Fig. 3. A common tendency for parameter A is to increase following a temperature rise. This means that the grading parameter of soil pore diameter $c$ will increase. According to Eq. (17), the computed values are $c_{6}=2.53$ and $c_{36}=3.27$ for lou soil, and $c_{6}=2.27$ and $c_{36}=2.73$ for Loess soil.

For sandy soils with low clay content, the variation in soil pore diameters can be ignored. Eq. (15) is simplified as follows:

$K_{T}(\theta)=\lambda^{2 c+1} \frac{v_{T o}}{v_{T}} K_{T o}(\theta)$

\subsection{Soil-water diffusivity}

According to Buckingham-Darcy's law, soil-water diffusivity, $D(\theta)$, can be expressed as follows (Hillel, 1980):

$D(\theta)=-K(\theta) \frac{\mathrm{d} h}{\mathrm{~d} \theta}$

At any temperature $T$ and a reference temperature $T_{0}$, temperature dependence of $D(\theta)$ can be deduced by combining Eqs. (16) and
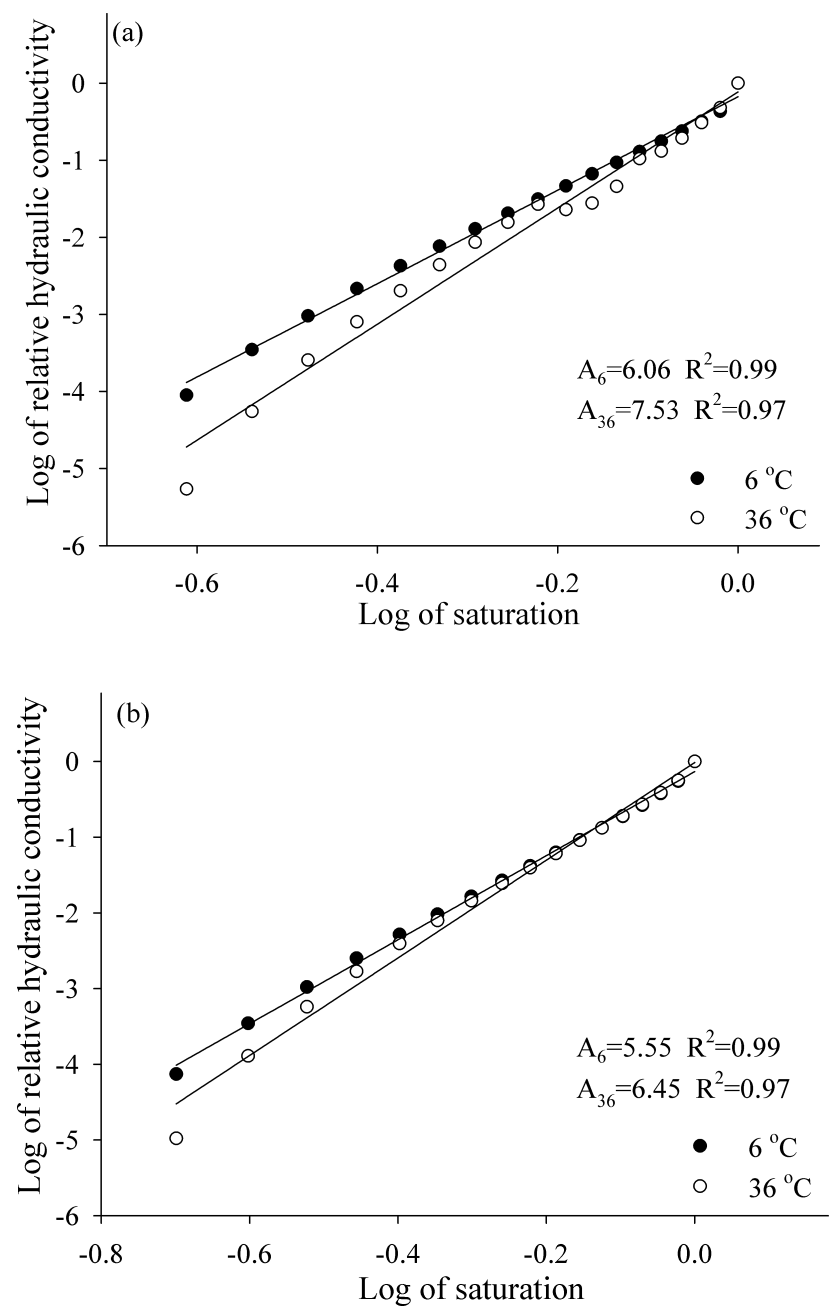

Fig. 3. The logarithmic form of relative hydraulic conductivity vs saturation for (a) lou soil and (b) sandy loess based on measurements at $6^{\circ} \mathrm{C}$ and $36^{\circ} \mathrm{C}$. A: the slope of the linear fitting curve. $R$ : determination coefficient.
(20):

$D_{T}(\theta)=\lambda^{2 c_{T}} h_{T o}{ }^{2\left(c_{T o}-c_{T}\right)} \frac{v_{T o}}{v_{T}} D_{T o}(\theta)$

For sandy soil with low clay content, the effect of temperature on $D(\theta)$ can be formulated as follows:

$D_{T}(\theta)=\lambda^{2 c} \frac{\nu_{T o}}{v_{T}} D_{T o}(\theta)$

\subsection{Soil-specific water capacity}

Soil-specific water capacity, $C(\theta)$, can be determined by:

$C(\theta)=\frac{K(\theta)}{D(\theta)}$

Specific water capacity can also be determined as a function of temperature. At different temperature $T$ and $T_{0}$, substituting (21) Eq. (16) and into Eq. (23) obtained:

$C_{T}(\theta)=\lambda C_{T o}(\theta)$

\section{Materials and methods}

Measurements were carried out on lou soil (Orthic Anthrosols) and sandy loess, which were first air-dried, ground and passed through a $1 \mathrm{~mm}$ sieve. The primary texture properties of the porous materials are shown in Table 1.

SWCC were measured using a high-speed refrigerated centrifuge (Model CR21G, Hitachi Co., Ltd., Japan). The temperature in the centrifugal chamber can be controlled by application settings (setting range: -20 to $40^{\circ} \mathrm{C}$ ). For every soil, sample cylinders ( $1.35 \mathrm{~g} \mathrm{~cm}^{-3}$ bulk density) in stainless steel sample retainers with $100 \mathrm{~cm}^{3}$ (5.05 cm inner-diam., $5.0 \mathrm{~cm}$ height) were first saturated for $24 \mathrm{~h}$ and then weighed to determine the soil water content at saturation. A centrifuge water extraction method was then applied. In the centrifuge, each sample retainer filled with soil was inserted into a stainless steel sample holder (Fig. 4). A drilled metallic plate and $205-\mu \mathrm{m}$ filter paper were placed at the bottom of the sample holder to facilitate retention of soil particles and drainage during centrifugation (Reatto et al., 2008). Before the first centrifugation step of each batch soil samples (4 soil cylinders of 2 per soil type), care was taken to keep the samples under a constant temperature for more than $180 \mathrm{~min}$ in the centrifuge without any operations in order to equalize with the given temperature. After each centrifugation step, the samples were weighed and returned to the centrifuge to undergo a higher rotation speed. This procedure was repeated for every rotation speed (Table 2 ). The samples were then oven dried at $105^{\circ} \mathrm{C}$ for $24 \mathrm{~h}$ to obtain the soil dry mass. The temperatures used were $6^{\circ} \mathrm{C}, 18^{\circ} \mathrm{C}$ and $36^{\circ} \mathrm{C}$ in this experiment.

Hydraulic conductivity $\left(K_{\mathrm{s}}\right.$ and $K(\theta)$ ) was measured using the method described by Haridasan and Jensen (1972). $K_{\mathrm{s}}$ and $K(\theta)$ were determined at different temperatures for different soils using a Lucite flow cell with inside dimensions of $h=0.4 \mathrm{~m}, d=0.10 \mathrm{~m}$,

Table 1

Soil textural properties of experimental soils

\begin{tabular}{llllll}
\hline Soils & Samples & $\begin{array}{l}\text { Sampling } \\
\text { Depth }(\mathrm{cm})\end{array}$ & \multicolumn{3}{l}{ Particle content $(\%$, size mm) } \\
\cline { 3 - 6 } & & & $\begin{array}{l}\text { Sand } \\
(>0.05)\end{array}$ & $\begin{array}{l}\text { Silt } \\
(0.05-0.002)\end{array}$ & $\begin{array}{l}\text { Clay } \\
(<0.002)\end{array}$ \\
\hline Lou soil & 24 & $0-20$ & 7.36 & 60.40 & 32.24 \\
Sandy loess & 24 & $0-20$ & 34.09 & 52.60 & 13.31 \\
\hline
\end{tabular}




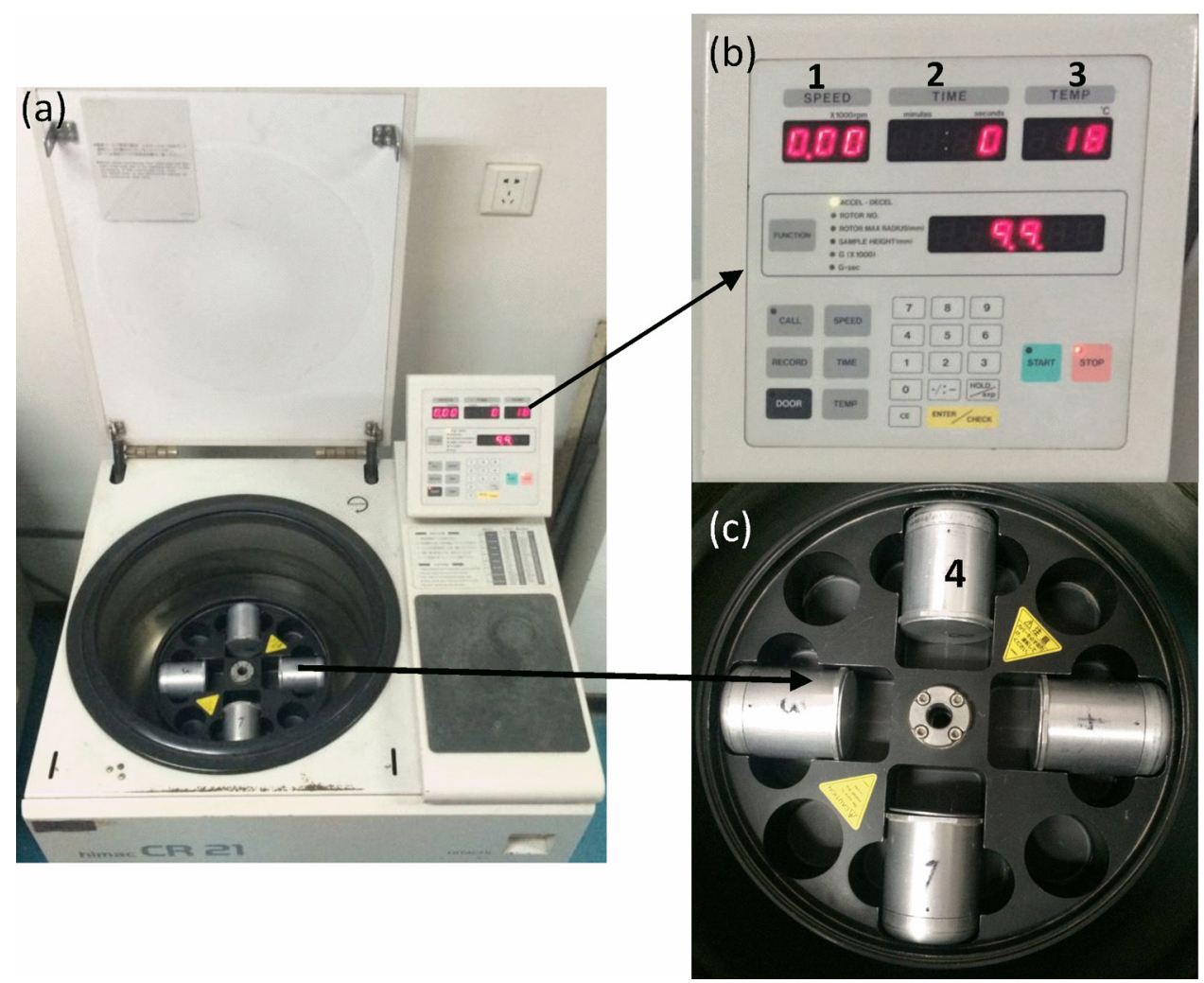

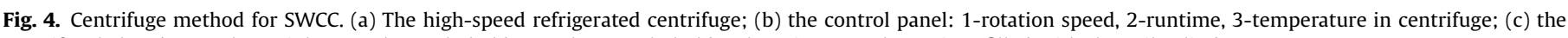
centrifugal chamber: 4-the stainless steel sample holder. In the sample holder there is a sample retainer filled with the soil cylinder.

Table 2

The general parameters in the procedure of centrifugation of soils at given temperature.

\begin{tabular}{llll}
\hline Samples & $\begin{array}{l}\text { Water potential } \\
(\mathrm{kPa})\end{array}$ & $\begin{array}{l}\text { Rotation speed } \\
(\mathrm{rpm})\end{array}$ & $\begin{array}{l}\text { Runtime } \\
(\mathrm{min})\end{array}$ \\
\hline & -1 & 310 & 10 \\
& -5 & 690 & 17 \\
& -10 & 980 & 26 \\
& -20 & 1390 & 36 \\
& -40 & 1960 & 45 \\
lou soil/ sandy loess & -60 & 2400 & 51 \\
& -80 & 2770 & 55 \\
& -100 & 3100 & 58 \\
& -200 & 4390 & 68 \\
& -400 & 6200 & 77 \\
& -600 & 7600 & 83 \\
& -800 & 8770 & 87 \\
& -1000 & 9810 & 90 \\
\hline
\end{tabular}

and $w=0.06 \mathrm{~m}$. Two porous Lucite plates with adhering filter papers were placed at the top and bottom to prevent spilling and leakage of soil. The flow cell was packed with air-dry soil which had first been passed through a $1 \mathrm{~mm}$ sieve. Bulk density of soil cylinder was controlled at $1.35 \mathrm{~g} \mathrm{~cm}^{-3}$. To prepare a homogeneous soil column, air-dry soil was added into the flow cell layer by layer $3 \mathrm{~cm}$ at a time. The soil porosity was based on the bulk density $\left(\rho_{b}\right)$ and specific density $\left(\rho_{s}\right)$ of soils: $f=1-\rho_{b} / \rho_{s}$.

Measurements on two columns corresponding to the two soil types were conducted in a closed phytotron with digitally controlled temperature and humidity. Soil columns were placed in the phytotron for $>3 \mathrm{~h}$ without any operations to equalize the soil temperature to the lab. During the experiments, the phytotron was closed completely to reduce disturbances from the external environment and to avoid temperature fluctuations.
Vertical infiltration measurements were carried out on the uniform soil samples to obtain the required data for calculating hydraulic conductivity (Eching et al., 1994). Constant-water head was maintained using a Mariotte bottle. The bubble point in the Mariotte bottle was slightly higher (less than $1 \mathrm{~cm}$ ) than the surface of the porous plate to keep a stable pressure head (Klute and Dirksen, 1986). The volume of water infiltrated into the soil was measured regularly through the liquid level changes in the Mariotte bottle. The distance of the wetting front was recorded visually and regularly. Volumetric water content $\left(\theta_{v}\right)$ was recorded at eight points along the column boundary by Time-domain Reflectometry (TDR). Four tensiometers were used to monitor the hydraulic gradient at $10 \mathrm{~cm}$ intervals along the Lucite columns. When the wetting front reached the position of the last tensiometer, the infiltration measurements for unsaturated hydraulic conductivity were terminated. The bottom of the column was covered with a sing-hole cap. The hole was connected to the atmosphere to maintain a constant pressure and to collect the water for the measurements of saturated hydraulic conductivity. The drying curves for hydraulic conductivity in this study were not monitored. The drying process was conducted through evaporation in a high temperature surrounding (not exceeding $60^{\circ} \mathrm{C}$ ) until the water content equilibrated.

The hydraulic conductivity measurements of the two soil columns were divided into three temperature phases, 6,18 , and $36^{\circ} \mathrm{C}$. During each phase of the experiment, wetting-drying cycles of each soil column were replicated three times while maintaining a constant temperature (Bachmann et al., 2002). In each wettingdrying cycle, process data, including wetting front and time, for hydraulic conductivity were recorded. At the end of the third wetting in each phase $K_{\mathrm{s}}$ was noted by collecting the water droppings at the bottom of the column. This was repeated three times for each temperature. For each soil type, all three 
measurement were conducted on the same packed soil column. The hydraulic diffusivity was measured by the same procedure for hydraulic conductivity except that the columns were placed horizontally (Bruce and Klute, 1956). Measurement results at $18^{\circ} \mathrm{C}$ were considered as the control test to obtain predicted data at other temperatures. Combining the observed data at $18^{\circ} \mathrm{C}$ with the aforementioned functions, we obtained predicted data at 6 and $36^{\circ} \mathrm{C}$. Based on measured data and the simulated data at 6 and $36^{\circ} \mathrm{C}$, comparative quantify were conducted to analyze the reliability of the proposed theory.

\section{Results and discussions}

\subsection{Temperature dependence of SWCC}

The van Genuchten model was used to fit the experimental data of SWCC for the two soils at three different temperatures (Fig. 5). Average values for saturated water content $\left(\theta_{\mathrm{s}}\right)$ and parameters $\alpha$ and $n$ at the three temperatures are listed in Table 3. At a given pressure head, volumetric water content increased as temperature decreased. In the region near saturation the different temperature curves overlapped each other for both soils. Schneider and Goss (2011) suggest that this is reasonable because the thick multilayer water film on minerals resembles pure water. The interaction energy of a water molecule adsorbing on such a multilayer water film is similar to adsorption on a pure water surface. Thus, with an
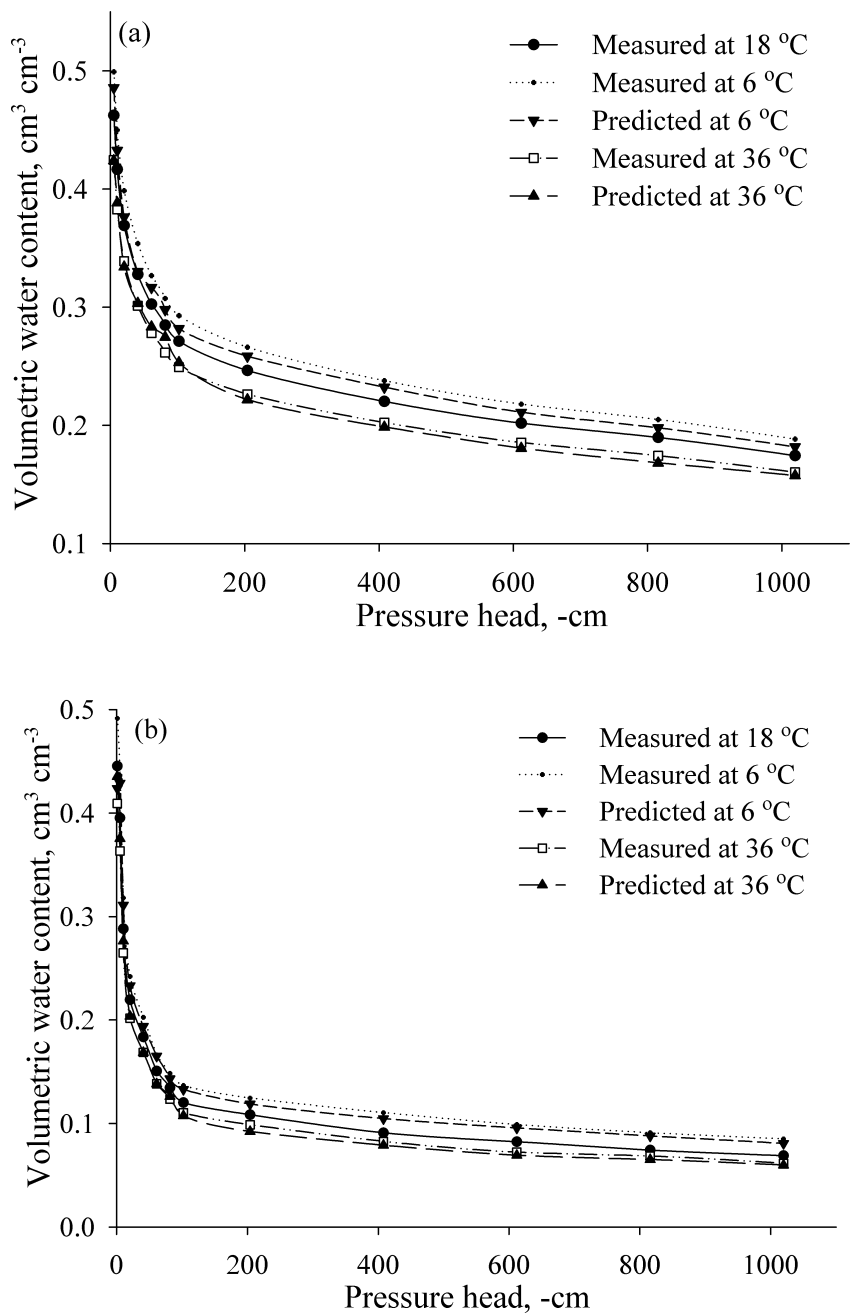

Fig. 5. Measured data and predicted data for SWCC of (a) lou soil and (b) sandy loess at $6^{\circ} \mathrm{C}, 18^{\circ} \mathrm{C}$ and $36^{\circ} \mathrm{C}$. The curve at $18^{\circ} \mathrm{C}$ represents the reference.
Table 3

Parameters in the Van Genuchten model in the tested soils at different temperatures.

\begin{tabular}{lllll}
\hline $\mathrm{T} /{ }^{\circ} \mathrm{C}$ & $\begin{array}{l}\text { Lou soil } \\
n\end{array}$ & $\alpha$ & $\theta_{\mathrm{r}} / \mathrm{cm}^{3} \mathrm{~cm}^{-3}$ & $\theta_{\mathrm{s}} / \mathrm{cm}^{3} \mathrm{~cm}^{-3}$ \\
\hline 6 & $2.013 \pm 0.15$ & $0.022 \pm 0.003$ & $0.095 \pm 0.006$ & $0.437 \pm 0.021$ \\
18 & $2.112 \pm 0.22$ & $0.022 \pm 0.008$ & $0.084 \pm 0.007$ & $0.433 \pm 0.028$ \\
36 & $2.367 \pm 0.14$ & $0.016 \pm 0.006$ & $0.079 \pm 0.005$ & $0.418 \pm 0.018$ \\
\hline $\mathrm{T} /{ }^{\circ} \mathrm{C}$ & Sandy loess & & & \\
& $n$ & $\alpha$ & $\theta_{\mathrm{r}} / \mathrm{cm}^{3} \mathrm{~cm}^{-3}$ & $\theta_{\mathrm{s}} / \mathrm{cm}^{3} \mathrm{~cm}^{-3}$ \\
\hline 6 & $2.412 \pm 0.18$ & $0.149 \pm 0.019$ & $0.070 \pm 0.006$ & $0.395 \pm 0.032$ \\
18 & $2.442 \pm 0.26$ & $0.142 \pm 0.027$ & $0.066 \pm 0.006$ & $0.384 \pm 0.028$ \\
36 & $2.633 \pm 0.24$ & $0.117 \pm 0.02$ & $0.058 \pm 0.004$ & $0.368 \pm 0.028$ \\
\hline
\end{tabular}

increase in water pressure head temperature dependence of soil water becomes greater because of the additional interactions water undergoes as the water film becomes thinner. A decrease in parameter $\alpha$ indicates a reduction in the water holding capacity of the soil as temperature increase. Temperature dependence of $\theta_{s}$ and $\theta_{r}$ are closely associated with the thermal properties of the liquid-solid interface. The parameter $n$, a shape parameter corresponding to the pore size distribution affecting the slope of the retention curve, increased as temperature rose demonstrating the effect of temperature change on soil porosity (van Genuchten et al., 1991).

The retention capability of a soil generally results from the equilibrium between stresses in the fluid phase, capillary forces acting at the interface of each phase, and attractive forces between water and soil particles. A change in temperature modifies the properties of the soil phases and also the interfaces (François and Ettahiri, 2012). Temperature dependence of retention capability is explained by a well-known mechanism of thermal-dependent surface tension (Philip and de Vries, 1957). Some researchers have speculated about the temperature dependence of the water-solid interface. In clay soils, pure water can be stored in the diffuse double layer of the clay platelets. In that zone, the cations of water are strongly attracted by soil particles. The thickness of this diffuse double layer is affected by temperature. With temperature increases, the expansion of the water adhered to the clay particles causes a decrease in the external specific surface of the major clay minerals, or pore size distribution (parameter $n$ in van Genuchten model). François and Ettahiri (2012) suggested that the variation of water content with temperature change could be considered as the sum of temperature-dependent changes in surface tension of the air-water interface and the change in thickness of the double layer of clay. They also provided an expression to describe the thermal mechanism and obtained excellent results between measured and predicted SWCC curves for four soils (MLD Clayey, Boom Clay, FoCa clay, Clay Salty sand and FEBEX Bentonite) at elevated temperatures. According to Eq. (5) and the measured data at $18^{\circ} \mathrm{C}$, the predicted SWCC for the two soils at $6^{\circ} \mathrm{C}$ and $36^{\circ} \mathrm{C}$ are shown in Fig. 5 . The predicted results were less than the experimental curves but were similar. The mean gaps between predicted and measured results were less than $0.007 \mathrm{~cm}^{3} \mathrm{~cm}^{-3}$ for lou soil and $0.004 \mathrm{~cm}^{3}$ $\mathrm{cm}^{-3}$ for Loess soil. The slope of the predicted and experimental values was nearly equal to 1 .

\subsection{Temperature dependence of saturated hydraulic conductivity}

Saturated hydraulic conductivity was also measured at $24^{\circ} \mathrm{C}$ and added to the dataset (measured at $6{ }^{\circ} \mathrm{C}, 18^{\circ} \mathrm{C}$ and $36^{\circ} \mathrm{C}$ ) to reflect the temperature dependent effect on $K_{\mathrm{s}}$ more reliably. The observed data for both soils were plotted in Fig. $6 . K_{s}$ significantly increased linearly with increasing temperature. The temperature dependent growth rate $d K_{s} / d T$ was $8.54 \times 10^{-5} \mathrm{~cm} \mathrm{~min}^{-1} \mathrm{~K}^{-1}$ for 

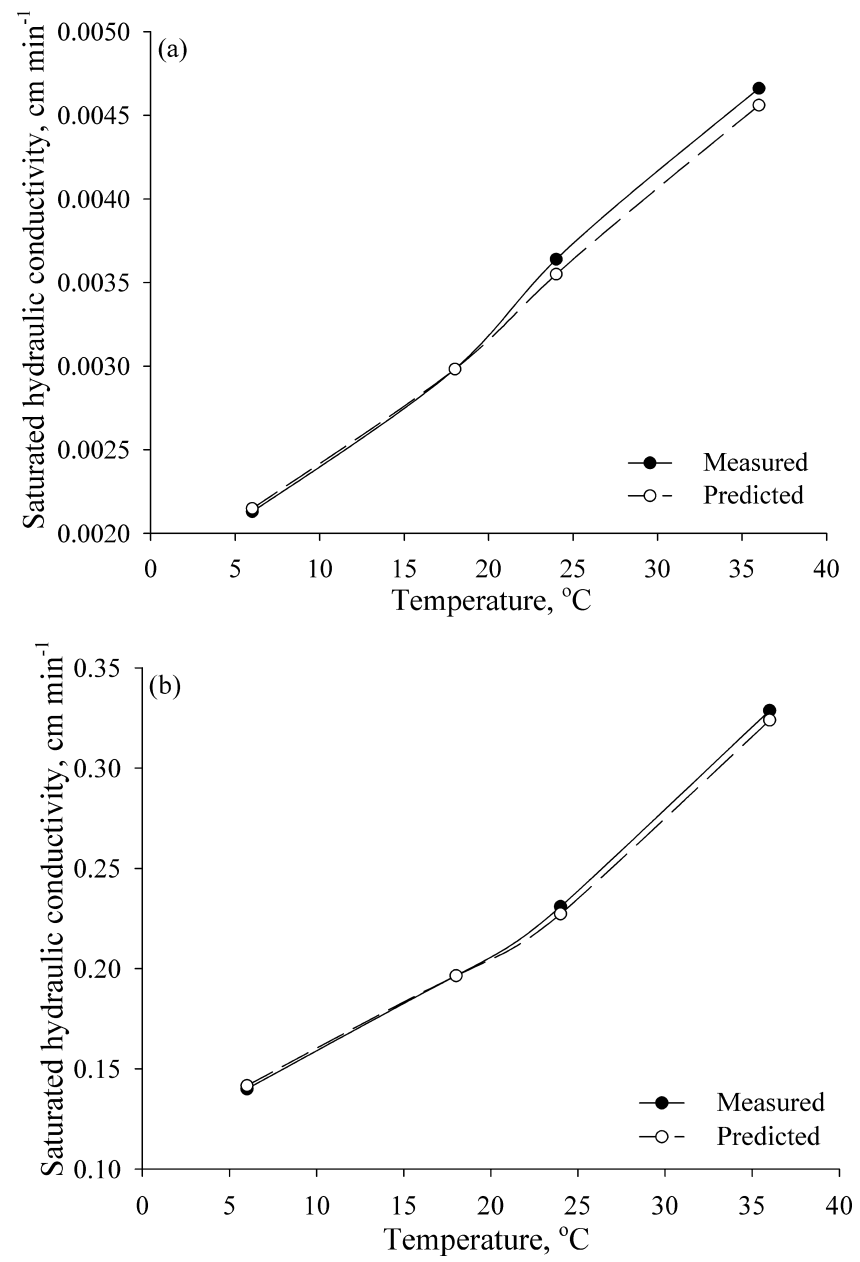

Fig. 6. Measured curves and predicted curves of saturated hydraulic conductivity $\left(K_{\mathrm{s}}\right)$ at $6^{\circ} \mathrm{C}, 18^{\circ} \mathrm{C}, 24^{\circ} \mathrm{C}$ and $36^{\circ} \mathrm{C}$.

lou soil and $0.0063 \mathrm{~cm} \mathrm{~min}^{-1} \mathrm{~K}^{-1}$ for sandy loess. The $K_{s}$ value for lou soil at $36^{\circ} \mathrm{C}$ was approximately 2.2 times greater than at $6^{\circ} \mathrm{C}$ and 2.35 times greater for sandy loess.

The expected data for $K_{\mathrm{s}}$ were obtained using Eq. (12) and measured data were collected at a reference temperature of $18^{\circ} \mathrm{C}$. Although the predicted and experimental curves of hydraulic conductivity are fairly close, a slight difference was seen as temperature increased. When temperatures were lower than $18^{\circ} \mathrm{C}$, the curves from measured and predicted are almost superposed for both soils. As the temperature increased, the differences between the observed and predicted values in the lou soil deviated. This trend is not observed for the sandy loess. This may be attributed to differences in soil pore structure and clay content. The temperature dependence of saturated hydraulic conductivity could be the result of the thermal effect of kinematic viscosity. Under saturated conditions, soil water suction remains zero no matter how much the temperature changes. According to the temperature dependent change of surface tension and kinematic viscosity, a temperature increase reduces the friction between water and solid particles. According to Eq. (12), the parameter M for lou soil and Sand loess were 0.05 and 3.33 , respectively.

\subsection{Temperature dependence of unsaturated hydraulic conductivity}

Measured values of unsaturated hydraulic conductivity $(K)$ for the two soils at different temperatures were plotted as a function of volumetric water content in Fig 7. It is apparent from Fig. 7 that
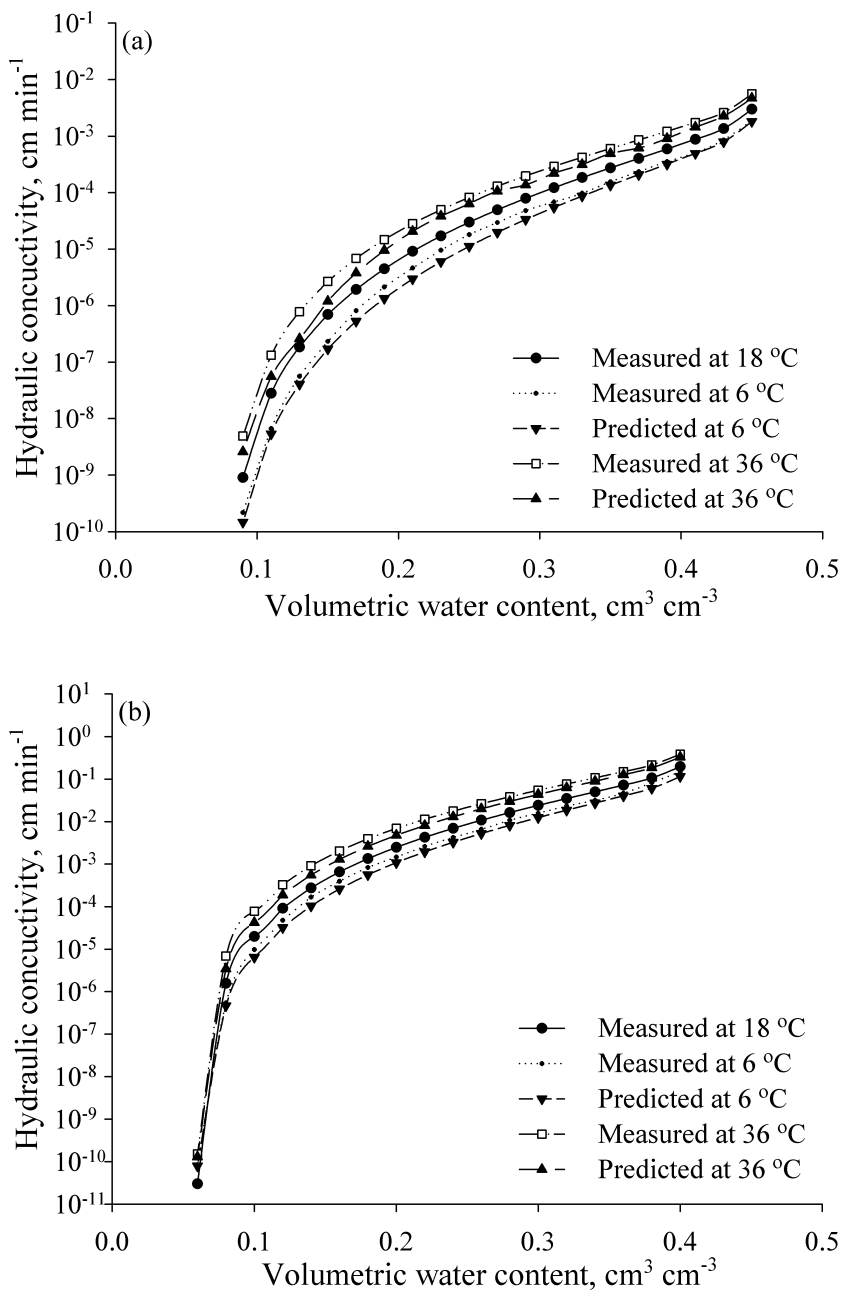

Fig. 7. Measured and predicted curves of unsaturated hydraulic conductivity of (a) lou soil and (b) sandy loess at $6^{\circ} \mathrm{C}, 18^{\circ} \mathrm{C}$ and $36^{\circ} \mathrm{C}$. The curve at $18^{\circ} \mathrm{C}$ indicates the reference..

as temperature increased hydraulic conductivity increased as well. For the lou soil, the range of variation of $K$ under different volumetric water contents was approximately $0-0.002 \mathrm{~cm} \mathrm{~min}^{-1}$ at $6^{\circ} \mathrm{C}$ and $0-0.006 \mathrm{~cm} \mathrm{~min}^{-1}$ at $36^{\circ} \mathrm{C}$. For the loess soil, values were approximately 0 to $0.12 \mathrm{~cm} \mathrm{~min}^{-1}$ at $6^{\circ} \mathrm{C}$ and $0-0.4 \mathrm{~cm} \mathrm{~min}^{-1}$ at $36^{\circ} \mathrm{C}$. $K$ values for both soils increased more than three times between at $6{ }^{\circ} \mathrm{C}$ and at $36^{\circ} \mathrm{C}$.

Previous research has proposed that increases in conductivity with an increase in temperature at a given water content is due to a decrease in water viscosity (Haridasan and Jensen, 1972). However, comparing the temperature dependent values of the experimentally determined conductivity ratios to the corresponding viscosity ratios, Hopmans and Dane (1986a) found that measured conductivities increased more rapidly with temperature than predicted, especially at the lower water contents and higher temperatures. They speculated that water conductivity might be overestimated during measurement due to the contribution of vapor movement, although there was no clear evidence for this. Gupta and Swartzendruber (1964) used the change in volume of entrapped air to explain the observed difference, but others debate that this mechanism has little or no effect on hydraulic conductivity.

To further assess the temperature dependence of unsaturated hydraulic conductivity, analyses were conducted to account for the impact of porosity change and water properties using Eq. (16). Examples of $K$ vs $\theta_{\mathrm{v}}$ for lou soil at $6^{\circ} \mathrm{C}$ and $36^{\circ} \mathrm{C}$ are presented in Fig. 8. Results show that the impact from temperature dependent 

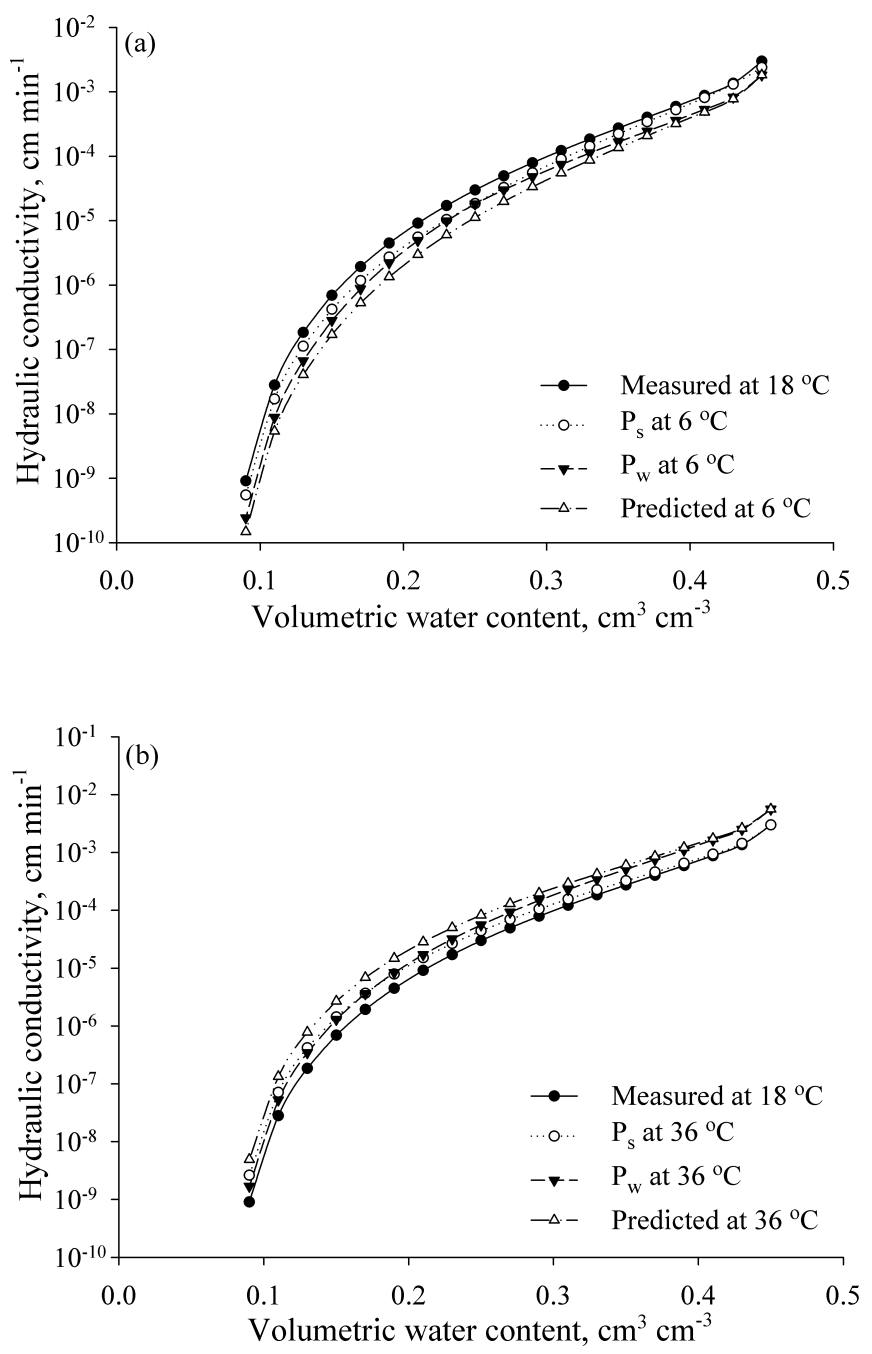

Fig. 8. Predicted unsaturated hydraulic conductivity curves for lou soils at (a) $6{ }^{\circ} \mathrm{C}$ and (b) $36^{\circ} \mathrm{C}$. The measured curve at $18{ }^{\circ} \mathrm{C}$ represents the control experiment; $P_{s}$ curve represents the predicted data only considering soil porosity change; $P_{\mathrm{w}}$ curve represents the predicted data only considering soil capillary change; predicted curve at $6^{\circ} \mathrm{C}$ and $36^{\circ} \mathrm{C}$ represents the predicted data considering both soil porosity change and soil capillary properties.

changes in water properties was greater than soil pore structure changes. In Fig. 8a the $P_{\mathrm{s}}$ curve was slightly lower than the measured curve at $18^{\circ} \mathrm{C}$. In Fig. $8 \mathrm{~b}$, the $P_{\mathrm{s}}$ curve was slightly above the measured curve at $18^{\circ} \mathrm{C}$. The corresponding $P_{\mathrm{w}}$ curve was closer to the predicted data at $6^{\circ} \mathrm{C}$ and $36^{\circ} \mathrm{C}$. The temperature dependence of water properties, including surface tension, kinematic viscosity and density of water, appear to be the dominant factors describing the temperature dependence of hydraulic conductivity.

Curves in Fig. 3 reflect an increase in parameter $c$ as temperature increases. The increase in parameter $c$ indicates the expansion of soil particles, especially in heavy loam with high clay content (Plum and Esrig, 1969; Agar et al., 1987; Murata and Kukawa, 1992; Hueckel et al., 2011). From a macroscopic view, a reduction in the void ratio with temperature increases is a result of particle swelling. Increases in temperatures reducing inter-particle bond strength between mineral particles and water can result in a reduction in the void ratio. Meanwhile, the expansion of particles also causes a reduction in specific surface area. This means that water holding capacity of particles decrease. Additionally, thermochemical effects alter clay fabric (flocculation or dispersion), porosity redistribution (creating preferential pathways or blocking macrospores), and pore fluid chemistry (affecting viscosity). The swelling behavior of clay particles is controlled by mineralogy and compositional properties (Baldi et al., 1988). Due to a high content of exchangeable cations, clay has strong plasticity and absorptivity, which are strongly influenced by thermal changes (Mellor, 1922).

A more common theory to explain the temperature dependent change in clay particles is the change in thickness of the double layer of clay (physical-chemical mineral-water interactions) with increased temperature during permeability. An increase in temperature can cause a thermal agitation of the water molecules bound to the clay particles, enabling them to move out of the bound layer with greater ease. The thickness of the bound water layer decreases because of the expelled water molecules, resulting in larger channels for water movement, and a higher permeability (Paaswell, 1967; Delage et al., 2000). Although the effects from soil particles are not significant in this study, the term $h_{T o}{ }^{2\left(c_{T O}-c_{T}\right)}$ shows that the temperature dependence of soil particles mainly affects the water-holding capacity of soils. With temperature increases the value of $\left(c_{T o}-c_{T}\right)$ is less than 0 , meaning a decrease in soil water suction. For soils with lower clay content this has little or no effect on hydraulic conductivity. Attention should be given to the multiplication relationship between the temperature dependence of water properties and temperature dependence of soil porosity, which is different from the superimposition proposed by previous research. Thus, further research is needed to explain this divergence.

\subsection{Temperature dependence of soil-water diffusivity}

Observed soil-water diffusivity vs volumetric water content for the two soils at different temperatures are shown in Fig. 9. As temperature increased a significant increase in soil-water diffusivity of the soils was observed. The diffusivity of Lou soil at $36^{\circ} \mathrm{C}$ was nearly three times greater than at $6^{\circ} \mathrm{C}$. A similar change was observed in the sandy loess soil. For the given soils, the magnitude of soil-water diffusivity showed a dependency on soil water content. At near or full saturation, soil-water diffusivity of the two soils showed a rapid increase at all temperatures. The change in soil water diffusivity of Lou soil was more pronounced.

It is easy to arbitrarily conclude that temperature dependence of soil-water diffusivity should be directly proportional to the surface tension and inversely proportional to the viscosity of water owing to Eq. (20). This relationship has been widely used to explain the thermal effect of hydraulic diffusivity (Jackson, 1963). However, Gardner (1959) suggested that the thermal effect of surface tension-viscosity is limited. His measured results of soilwater diffusivities at several temperatures indicated that the temperature coefficient of soil water diffusivity may be positive or negative depending on soil texture. According to Eq. (21), the expected diffusivity considering soil porosity change of the two soils at $6^{\circ} \mathrm{C}$ and $36^{\circ} \mathrm{C}$ was calculated (Fig. 9). The nearly identical measured and predicted curves suggest that the temperature dependence of diffusivity in soils is influenced by the integration of tension-viscosity soil porosity. The term $\left(c_{T o}-c_{T}\right)$ in Eq. (21) reflects the thermal effect of soil porosity.

\section{Conclusions}

In this study, formulas defining the temperature dependence of water surface tension-viscosity and soil porosity were proposed to quantify the effect of temperature on soil hydraulic parameters including SWCC, hydraulic conductivity, soil-water diffusivity, and specific water-holding capacity. Two soils were used to obtain experimental data on soil hydraulic parameters at different temperatures. Based on the formulas and controlled experimental 

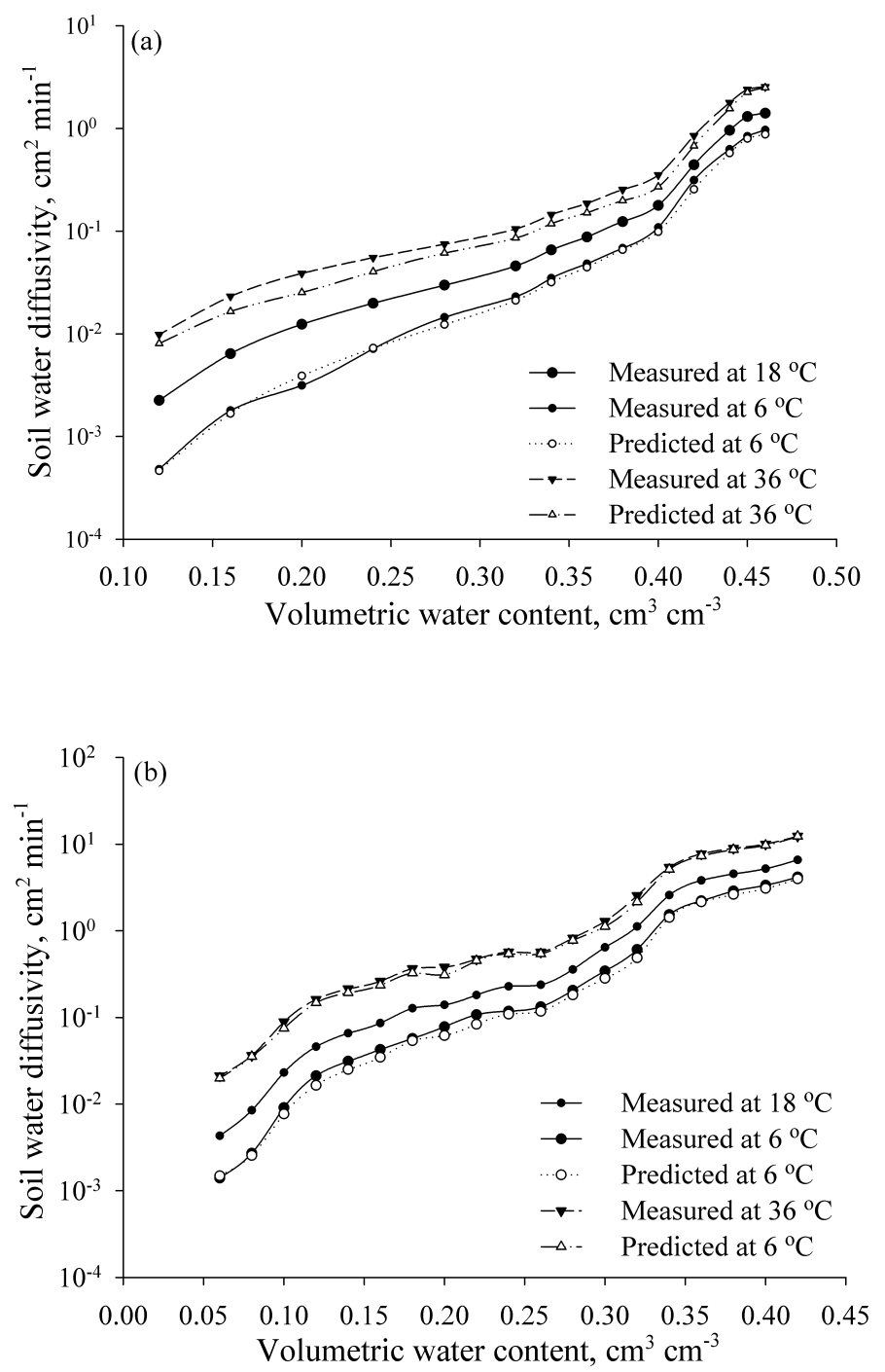

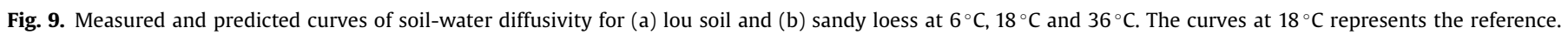

data, expected soil hydraulic parameters at given temperatures were calculated and compared with the corresponding measured results. Results showed that predicted and experimental curves for all of the soil hydraulic properties were fairly similar with small deviations at high temperatures.

Two temperature coefficients, $\lambda$ representing the thermal effect of water surficial properties and $c$ representing the thermal effect of soil particles on soil hydraulics were introduced into formulae to understand the magnitude of the temperature dependent effect. The temperature dependence of SWCC is the result of the temperature dependence of water surface tension and water density ( $\lambda$, the integrated representation in formula). Other factors such as entrapped air and water solution changes also likely influence SWCC (Hopmans and Dane 1986b). Temperature dependence of hydraulic conductivity can be attributed to the combined effects of water interface properties $(\lambda)$ and soil particles (c). An observed increase in parameter $c$ with temperature increases indicates the expansion of soil particles, which change soil pore characteristics and the interface between a liquid and solid. The relationship between the temperature dependence of water surficial properties and temperature dependence of soil particles is multiplicative.

\section{Acknowledgements}

This research is supported by the National key Natural Science Foundation of China, Project No. 91025018. We thank the editors of the journal and several reviewers for their help. We would also like to thank Alison Beamish at the University of British Columbia for her assistance with English language and grammatical editing of the manuscript.

\section{References}

Agar, J., Morgenstern, N., Scott, J., 1987. Shear strength and stress-strain behaviour of Athabasca oil sand at elevated temperatures and pressures. Can. Geotech. J. 24 (1), 1-10.

Bachmann, J., Horton, R., Grant, S.A., Van der Ploeg, R.R., 2002. Temperature dependence of water retention curves for wettable and water-repellent soils. Soil Sci. Soc. Am. J. 66 (1), 44-52.

Baldi, G., Hueckel, T., Pellegrini, R., 1988. Thermal volume changes of the mineralwater system in low-porosity clay soils. Can. Geotech. J. 25 (4), 807-825.

Bruce, R., Klute, A., 1956. The measurement of soil moisture diffusivity. Soil Sci. Soc. Am. J. 20 (4), 458-462.

Chen, Y., Schnitzer, M., 1978. The surface tension of aqueous solutions of soil humic substances. Soil Sci. 125 (1), 7-15.

Constantz, J., 1982. Temperature dependence of unsaturated hydraulic conductivity of two soils. Soil Sci. Soc. Am. J. 46 (3), 466-470. 
Constantz, J., Murphy, F., 1991. The temperature dependence of ponded infiltration under isothermal conditions. J. Hydrol. 122 (1), 119-128.

Delage, P., Sultan, N., Cui, Y.J., 2000. On the thermal consolidation of Boom clay. Can. Geotech. J. 37 (2), 343-354.

Eching, S.O., Hopmans, J.W., Wendroth, O., 1994. Unsaturated hydraulic conductivity from transient multistep outflow and soil water pressure data. Soil Sci. Soc. Am. J. 58 (3), 687-695.

Flocker, W.J., Yamaguchi, M., Nielsen, D.R., 1968. Capillary conductivity and soil water diffusivity values from vertical soil columns1. Agron. J. 60 (6), 605-610.

François, B., Ettahiri, S., 2012. Role of the soil mineralogy on the temperature dependence of the water retention curve. Unsaturated Soils: Research and Applications. Springer, Berlin Heidelberg, pp. 173-178.

Gardner, W., 1959. Diffusivity of soil water during sorption as affected by temperature. Soil Sci. Soc. Am. J. 23 (6), 406-407.

Grant, S.A., Bachmann, J., 2002. Effect of temperature on capillary pressure. Environmental Mechanics: Water, Mass and Energy Transfer in the Biosphere, 199-212. The Philip.

Gupta, R.P., Swartzendruber, D., 1964. Entrapped air content and hydraulic conductivity of quartz sand during prolonged liquid flow. Soil Sci. Soc. Am. J. 28 (1), 9-12.

Haridasan, M., Jensen, R.D., 1972. Effect Of temperature on pressure head-water content relationship and conductivity of two soils. Soil Sci. Soc. Am. J. 36 (5), 703-708.

Hillel, D., 1980. Fundamentals of Soil Physics. Academic Press, Inc. (London) Ltd..

Hopmans, J., Dane, J.H., 1985. Effect of temperature-dependent hydraulic properties on soil water movement. Soil Sci. Soc. Am. J. 49 (1), 51-58.

Hopmans, J.W., Dane, J.H., 1986a. Temperature dependence of soil hydraulic propeties. Soil Sci. Soc. Am. J. 50, 4-9.

Hopmans, J.W., Dane, J.H., 1986b. Temperature dependence of soil water retention curves. Soil Sci. Soc. Am. J. 50 (1), 562-567.

Hueckel, T., Francois, B., Laloui, L., 2011. Temperature-dependent internal friction of clay in a cylindrical heat source problem. Geotechnique 61 (10), 831-844.

Jackson, R.D., 1963. Temperature and soil-water diffusivity relations. Soil Sci. Soc. Am. J. 27 (4), 363-366.

King, P.M., 1981. Comparison of methods for measuring severity of water repellence of sandy soils and assessment of some factors that affect its measurement. Aust. J. Soil Res. 19, 275-285.

Klute, A., Dirksen, C. 1986. Hydraulic conductivity and diffusivity: Laboratory methods. Methods of Soil Analysis: Part 1-Physical and Mineralogical Methods: 687-734.
Liu, M.X., Cui, W.H., Wu, D., Liao, L.J., Du, W.Z., 2014. Soil macropore structures and their effect on preferential flow. Appl. Mech. Mater. 522, 990-994.

Mellor, J., 1922. On the plasticity of clays. Trans. Faraday Soc. 17, 354-365.

Murata, J., Kukawa, H., 1992. Viscosity equation for fresh concrete. ACI Mater. J. 89 (3), 230-237.

Nimmo, J.R., Miller, E.E., 1986. The temperature dependence of isothermal moisture vs. potential characteristics of soils. Soil Sci. Soc. Am. J. 50 (5), 1105-1113.

Paaswell, R.E., 1967. Temperature effects on clay soil consolidation. Soil Mech. Found. Eng. ASCE 93 (SM3), 9-22.

Philip, J.R., 1957. The theory of infiltration: 4. Sorptivity and algebraic infiltration equations. Soil Sci. 84 (3), 257-264.

Philip, J., de Vries, D., 1957. Moisture movement in porous materials under temperature gradients. Eos. Trans. AGU 38, 222-232.

Plum, R.L., Esrig, M.I., 1969. Some temperature effects on soil compressibility and pore water pressure. Highway Res. Board Special Rep. 103.

Poiseuille, J.M., 1844. Recherches expérimentales sur le mouvement des liquides dans les tubes de très-petits diamètres, Imprimerie Royale.

Reatto, A., Da Silva, E.M., Bruand, A., Martins, E.S., Lima, J.E.F.W., 2008. Validity of the centrifuge method for determining the water retention properties of tropical soils all rights reserved. Soil Sci. Soc. Am. J. 72 (6), 1547-1553.

Romero, E., Gens, A., Lloret, A., 2001. Temperature effects on the hydraulic behaviour of an unsaturated clay. Geotech. Geol. Eng. 19 (3-4), 311-332.

Schneider, M., Goss, K.U., 2011. Temperature dependence of the water retention curve for dry soils. Water Resour. Res. 47 (3), W03506.

Shao, M.A., Horton, R., 1998. Integral method for estimating soil hydraulic properties. Soil Sci. Soc. Am. J. 62 (3), 585-592.

She, H.Y., Sleep, B.E., 1998. The effect of temperature on capillary pressuresaturation relationships for air-water and perchloroethylene-water systems. Water Resour. Res. 34 (10), 2587-2597.

van Genuchten, M.T., 1980. A closed-form equation for predicting the hydraulic conductivity of unsaturated soils. Soil Sci. Sco. Am. J. 44 (5), 892-898.

van Genuchten, M.T., Nielsen, D.R., 1985. On describing and predicting the hydraulic properties of unsaturated soils. Ann. Geophys. 3 (5), 615-628.

van Genuchten, M.T., Leij, F., Yates, S., 1991. The RETC Code For Quantifying The Hydraulic Functions Of Unsaturated Soils. In: Robert, S. (Ed.), Kerr Environmental Research Laboratory.

Wilkinson, G.E., Klute, A., 1962. The temperature effect on the equilibrium energy status of water held by porous media. Soil Sci. Soc. Am. J. 26 (4), 326-329. 